\title{
A PERDA DE AUTORIDADE E TRADIÇÃO: A CRISE NA EDUCAÇÃO COMO CRISE NA MODERNIDADE SEGUNDO O PENSAMENTO DE HANNAH ARENDT
}

\author{
LOSS OF AUTHORITY AND TRADITION: THE CRISIS IN EDUCATION AS A \\ CRISIS IN MODERNITY ACCORDING TO HANNAH ARENDT'S THOUGHT
}

\author{
Matheus Henrique Luchesi ${ }^{1}$
}

RESUMO: Através de uma perspectiva filosófica, o artigo elaborado apresenta a relação entre os conceitos de educação e liberdade segundo o pensamento de Hannah Arendt. Embora a autora não explicite os conceitos de uma maneira específica, encontramos em seu pensamento uma relação essencial entre os mesmos. O conceito fundamental que conduz todo o artigo é o de natalidade, uma vez que os seres novos já nascem em um mundo constituído. Partindo dessa condição é visível a potencialidade do ser humano que por sua liberdade torna-se capaz de iniciar algo novo, considerando-o que estes, precisam ser acolhidos em um espaço comum que seja mais velho do que eles, pois, neste tempo e espaço por ele a ser percorrido, o mesmo poderá experimentar e vivenciar o passado apoiado na tradição que os impulsionará ao futuro, tornando-se assim, apto e maduro para enfrentar os desafios e crises atuais. Contudo, o papel da educação é contribuir para que os recém-chegados, tomem posse e usufruem desse mundo que lhes é legado, para que no futuro possam assumir a responsabilidade por ele.

Palavras-Chave: Autoridade. Crise. Educação. Natalidade. Tradição.

ABSTRACT: Through a philosophical perspective, the article presents the relationship between the concepts of education and freedom according to Hannah Arendt's thinking. Although the author does not explain the concepts in a specific way, we find in her thought an essential relationship between them. The fundamental concept that drives the entire article is that of birth, since new beings are already born in a constituted world. Based on this condition, the potential of the human being is visible, who, due to his freedom, becomes able to start something new, considering that they need to be welcomed in a common space that is older than them, because, in this time and space through it, it will be able to experience and

\footnotetext{
${ }^{1}$ Bacharelando em Teologia pela Universidade Cruzeiro do Sul, licenciado em Filosofia pela Instituição Claretiano Centro Universitário, especialista em aconselhamento filosofico pela Instituição Claretiano Centro Universitário, pós-Graduação em Neurociência pela FCE Faculdade Campos Elíseos; PósGraduação: Educação Musical pela FCE- Faculdade Campos Elíseos. E-mail: matheusluchesir@hotmail.com.
} 
live the past supported by the tradition that will propel them to the future, thus becoming, apt and mature to face the current challenges and crises. However, the role of education is to help newcomers to take possession and enjoy this world that is left to them, so that in the future they can take responsibility for it.

Keywords: Authority. Crisis. Education. Tradition.

\section{INTRODUÇÃO}

Para se falar de Hannah Arendt se faz necessário "pensar" e "agir" por amor ao mundo, no qual cuja vida foi dedicada para o pensamento e a ação da mesma no mundo contemporâneo. É fundamental referir-se ao mundo, pois não há uma vida que mereça ser contada sem que se deixe suas marcas, seja porque contribuíra para sua transformação, seja porque compreendera tais transformações.

Vinda de uma família de Judeus não-praticantes, a pensadora alemã Hannah Arendt cresce sob os preceitos de Goethe, que privilegiam a responsabilidade pelos outros, a autodisciplina, dado que, assume o judaísmo como identidade política. Com pais intelectualizados e politizados, Arendt aproximou-se dos socialistas já na adolescência, pois, da relação intensa e secreta com Martin Heidegger em sua juventude, Hannah absorve ideias que influenciara seu trabalho para o resto da vida.

Nem liberal, nem marxista, o pensamento de Arendt trabalha a tradição filosófico política, pois, engaja seu pensamento na tarefa política de compreender a crise na modernidade, sendo assim, explanar a "crise na Educação".

Só é possível entender a crise que abrange o mundo moderno e interfere toda a esfera da educação em um dos artigos de Hannah Arendt "A crise na educação", onde a autora explana o seu ponto de vista sobre a educação. Logo de imediato nos deparamos com uma grande oportunidade que a crise pode nos proporcionar, ou seja, de olharmos para trás em buscas de respostas velhas que introduzirá os recém-chegados em um mundo novo, no que diz: "uma crise nos obriga a voltar às questões mesmas e exige respostas novas ou velhas, mas de qualquer modo julgamentos diretos" (ARENDT, 2003, p. 223). Com isso, nos colocamos diante de alguns desafios a refletir. O que é educação? Qual o sentido da educação? O porquê educar? E é nessa perspectiva de reflexões que Arendt nos conduzirá a descobrir o papel que a educação impõe a toda sociedade humana através das crianças, aqueles recém-chegados que vem para construir um novo mundo. 
O grande desafio provém daqueles que existiram e existem no mundo frente aqueles que acabaram de chegar, que começaram adentrar no espaço mundano. Os recém-chegados podem transmitir tanto um avanço quanto uma ameaça, pois visto que estes passam a existir no mundo, faz com que o mesmo não permaneça da mesma forma, ou seja, há grandes transformações, mudanças. Por isso, deve cada recém-chegado conheça o lugar que deverá habitar-se, o lugar que de certo modo será sua casa.

Arendt mostra que todos os desafios e toda a ação educativa está na própria essência da educação, na qual, destaca como: natalidade, ou seja, existe um mundo velho que acolhe os seres humanos novos que nele deverá familiarizar-se com o espaço e toda suas histórias. Nesse sentido, o papel da escola é apresentar aos seus alunos o mundo comum em seus saberes e práticas, aquilo que conquistou e aquilo que se tornou obra, os conflitos e desastres, enfim, tudo o que lhes antecederam e foram deixados como heranças e experiências humanas. Assim, a tarefa da educação é preservar todos os fatos que antecedem a chegada de qualquer indivíduo, quanto tudo aquilo que é compartilhado uns com os outros.

Cada criança nasce com algo novo, com uma nova iniciativa de transformação, de mudança, de renovação. Sendo assim, cabe à educação não somente proteger o mundo do que é imposto pelos novos, mas, acolhê-los e protegê-los do mundo que elas estão inseridas. É necessário de um espaço para desenvolver e apropriar-se; só assim a criança terá o engajamento no mundo compartilhado com os outros.

A educação tem por responsabilidade então de, receber a criança e preservar o mundo que ela habita. Eis o papel do professor:

Face à criança, é como se [...] fosse um representante de todos os habitantes adultos, apontando os detalhes e dizendo a criança: - Isso é o nosso mundo" (ARENDT, 2003, p. 239).

Nisso que consiste a tarefa da educação: receber aos recém-chegados, apresentar a eles o nosso mundo e convidá-los a fazer parte dele. Tal convite poderá ser feito somente por aqueles que são habitantes do mundo comum, não por aqueles que apenas estão no mundo por estadia, ou seja, somente o educador, o professor, que assume algum compromisso com o mundo público, pode, de fato, ensinar a educação - educar a criança.

É justamente nesse período de insatisfação, de falta de compromisso com o mundo comum que a crise se instala, pois, no momento que os seus habitantes se sentem impossibilitados de fazer parte deste mundo, o espaço público os torna responsáveis pelo que 
estes têm em comum uns com os outros. É o que explica Arendt em "A crise da educação Americana":

Esta apresenta um problema imensamente difícil por ter surgido sob as condições de uma sociedade de massas e em resposta às suas exigências" (ARENDT, 2003, p. 228).

A sociedade de massa para Arendt é a extinção do mundo comum. Há momentos em que os habitantes adultos não se sentem mais vocacionados a fazerem parte daquele mundo compartilhado, isto é, não assumem mais a responsabilidade por ele, então, não se pode cobrar dos professores esses deveres, dizendo que isso ocorre por causa da sua má vontade. Arendt apresenta o mundo como uma sociedade sem interesse, que não se pergunta quem são as pessoas, onde elas estão, que lugar elas ocupam, sendo assim, este passa a ser um espaço desagradável, elas não se "sentem em casa" e não tem vínculo algum com ele. Tudo isso ocorre devido à falta de responsabilidade do mundo em que vivemos junto aos outros.

As pessoas não querem mais exigir ou confiar a ninguém o ato de assumir a responsabilidade por tudo mais. O homem moderno [...] não poderia encontrar nenhuma expressão mais clara para sua insatisfação com o mundo, para seu desgosto com o estado de coisas, que sua recusa a assumir, em relação às crianças, a responsabilidade por tudo isso" (ARENDT, 2003, p. 24I).

O problema que lidamos na educação em relação ao mundo é justamente esta falta de responsabilidade dos mais velhos. Porém, diante das crianças, não importa se é difícil ou não assumir tal compromisso com o mundo, inicialmente é preciso inseri-la com determinação neste mundo, apresentando-as seus meios para a sobrevivência. Segundo Arendt, não são as metodologias de ensino ou os professores, ou até mesmo a falta de recursos o grande problema da educação, mas o rompimento que se tem com o mundo comum.

Qualquer pessoa que se recuse a assumir responsabilidade coletiva pelo mundo não deveria ter filhos, e é preciso proibi-la de tomar parte em sua educação" (ARENDT, 2033, p. 239).

Com essa afirmação, percebe-se que estar diante da crise implica a busca de respostas propícias ou específicas para enfrentá-la, mesmo não tendo uma luz que ilumine este caminho de incertezas. Então, enfatiza Arendt que, a atitude a ser tomada não poderia ser outra, uma vez que nos encontramos diante daqueles que dependem dos outros para serem "guiados através do mundo preestabelecido no qual nasceram como estrangeiros" (ARENDT, 2003, p. 
128). Porém, é preciso considerar que a perda de autoridade no mundo moderno, "na educação, ao contrário do mundo, não pode haver tal ambiguidade face à perda hodierna de autoridade" (ARENDT, 2003, p. 240).

No entanto, visto que não se faz presente a responsabilidade e a perda de autoridade e da tradição, não é possível educar e responsabilizar-se pelo mundo e pelas crianças, pois, os nossos grandes pilares com o mundo comum é: autoridade e tradição. Por isso, se faz necessário buscar e examinar a essência da educação e toda a sua contextualização segundo o pensamento da autora.

Ao pensar na educação, Hannah Arendt tem como referência o conjunto de problemas políticos cristalizados no tempo, pois percebe um certo desinteresse das pessoas adultas em relação à educação das crianças e dos jovens, ou seja, não há envolvimento e responsabilidade para com a educação destes. No ensaio A crise da educação, a autora apresenta uma importante reflexão sobre a educação. Em seu texto, a filósofa apresenta problemas contidos no sistema escolar norte-americano, ocorridos nos meados de 1950 a 196o; portanto, tal reflexão de Arendt aponta uma crise que perpassa as fronteiras norte-americanas, ou seja, uma crise que assola o mundo. Intervenção é a definição dada por Arendt sobre a palavra "crise"; esta não é um desastre ou um mal, mas é um momento de decisão do pensamento causado pelo rompimento do senso comum, ou seja, é a oportunidade de se pensar o novo, de raciocinar, de refletir sobre o novo. Sendo assim, a crise reveste-se de uma importância política de tal modo que, os conduz para uma reflexão profunda mediante o sentido da educação.

Uma crise nos obriga a voltar às questões mesmas e exige respostas velhas, mas de qualquer modo julgamentos diretos. (ARENDT, 20II, p. 223).

Segundo Arendt, existe uma contribuição da educação na formação das crianças e dos jovens, desde que seja apresentada para eles a cultura humana, ou seja, tudo aquilo que seus antepassados produziram e desenvolveram ao longo dos séculos. A proposta de Arendt é mostrar que a educação é discussão que deve ser do interesse de todos, não somente das escolas, pois, os adultos é que são responsáveis pela educação das crianças e dos jovens; a escola pode apenas agir como intermediadora entre o lar e o mundo comum.

[...] a escola não é de modo algum o mundo e não deve fingir sê-lo; ela é, em vez disso, a instituição que interpomos entre o domínio privado do lar e o mundo com o fito de fazer com que seja possível a 
transição, de alguma forma, da família para o mundo. (ARENDT, 20II, p. 238).

Por isso, pode-se dizer que a educação e a crise tornou-se tão agravante e amplas que se tornaram um problema político, pois, dado que ocorre a construção de um espaço político e a preservação do espaço público no mundo, todos devem deixar-se envolver pela humanidade.

Em A crise da educação percebe-se a tamanha profundidade das discussões que abordam a educação e a sua razão de ser através do conceito de natalidade onde afirma que: "a essência da educação é a natalidade, isto é, o fato que seres nascem para o mundo" (ARENDT, 20II, p. 223). Para Arendt, assim como qualquer animal, todos nós nos submetemos a um ciclo vital, o nascer para o mundo, visto que, o nascimento é o surgimento para a vida. Entendendo que além de tudo aquilo que construímos artificialmente, também nós nascemos para o mundo, pois, tudo aquilo que é criado artificialmente é construído pelos homens através das relações que os mesmos estabeleceram-se uns com os outros ao longo da história de suas vidas e ao longo de toda a história. "A natalidade, portanto, diz respeito à dinâmica entre o mundo historicamente constituído e a chegada dos novos que podem intervir nele" (ALMEIDA, 20II, p. 2I). Por isso, coube a autora enfatizar que cada geração deve retomar as gerações passadas ou anteriores, para que tudo aquilo que é político e cultural não desapareça com o passar dos tempos. No entanto, descreve este conceito de mundo como:

[...] aquilo que adentramos ao nascer e deixamos para trás quando morremos. Transcende a duração da nossa vida tanto no passado quanto no futuro, preexistia a nossa chegada e sobreviverá a nossa breve permanência nele. É isso o que temos em comum não só com aqueles que vivem conosco, mas também com aqueles que aqui estiveram antes e com aqueles que virão depois de nós. (ARENDT 2010, p. 67).

Sendo assim, Arendt busca através da discussão da crise na educação, mostrar o quanto se tem de importância o sentido da educação para a humanidade, pois nascemos para um conjunto de realizações humanas e não só para esta dimensão de vida, porém, é neste conjunto de realizações que todos nós adultos e recém-chegados devemos ser iniciados. Com isso, o sentido da educação se apresenta como o "respeito e a responsabilidade das antigas gerações adultos - para com os recém-chegados" (MULLER, 2012, p. 58). Para Almeida (2011, p. 2I) " os recém-chegados precisam ser acolhidos e familiarizados com este espaço comum e seu legado, 
que futuramente estarão sob sua responsabilidade. A tarefa da educação, é portanto, introduzir as crianças num mundo que lhes antecede e que continuará depois delas".

Vinculando-se a ideia de respeito e de responsabilidade que os adultos devem assumir para com os recém-chegados, Arendt propõe que estes, sendo eles, pais ou professores, têm por tarefa, garantir a existência do espaço público do mundo, de preservar o mundo comum, ou seja, de proporcionar espaço para que todos possam apresentar suas opiniões e assumirem suas próprias identidades. Assim, pode-se dizer que a esfera pública é o espaço da liberdade, "mas as crianças, embora potencialmente livres por terem nascidas, ainda não exercem sua liberdade nesse espaço comum" (ALMEIDA, 20II, p. 29), portanto, a defesa, a autoproteção, o bem-estar e o zelo pelos filhos são atributos necessários para a preservação das crianças, visto que tudo isso deverá provir dos pais para com os filhos. Sendo assim, os jovens quando imersos no mundo adulto, através de todos esses conhecimentos á eles transmitidos pelas antigas gerações, poderão adentrar no domínio político e conquistar sua própria autonomia, uma vez que os mesmos exponham suas opiniões e tudo aquilo que tem por seus pontos de vistas, só assim tornar-se-ão cidadãos responsáveis por si e pelo mundo público. Cabe-nos ressaltar que para Arendt é possível compreender os recém-chegados de duas maneiras: como jovem e como crianças. Os jovens e as crianças são aqueles que estão se preparando para o mundo, e depois como adulto que irá confirmar o seu nascimento no mundo. Assim, implica o significado do conceito ação que segundo Arendt tem o objetivo de:

Agir, em seu sentido mais geral, que significa tomar iniciativa, iniciar [...]. Por constituírem um initium, por serem recém-chegados e iniciadores em virtude do fato de terem nascido, os homens tomam iniciativas, são impelidos a agir [...] não é o início de algo, mas de alguém que é ele próprio, um iniciador. Com a criação do homem, veio ao mundo o próprio princípio do começar, e isso, naturalmente, é apenas outra maneira de dizer que o princípio da liberdade foi criado quando o homem foi criado, mas não antes. (ARENDT, 2010, p. 222).

Para Arendt, o papel da educação tem por objetivo deixar que os homens abram espaços entre si para se fazer política, onde através desse espaço de ação possibilitem a construção de um mundo comum entre os mesmos, sendo assim, afirma-se que a política é a atividade entre os homens. Porém, deve esta atividade atue em seus meios, mas para isso, estes necessitam de liberdade - espaço - onde cada um expõe suas opiniões. Assim, conclui-se que o papel da educação é encaminhar o recém-chegado para o mundo. 
Todo e qualquer ser humano pode se questionar, se perguntar ou até mesmo de expressar o que há em seu interior por meio da ação, do discurso, aí coloca suas argumentações e seu ponto de vista. Contudo, é no discurso, nesse momento de diálogo e interrogatórios que o ser humano se difere de outros; pois através do discurso é possível analisar a sua singularidade. O ser humano aparece no mundo desde apresenta-se dizendo quem ele é, ou seja, ele assumirá a sua própria identidade e nesse mundo faz com que ocorra as suas ações.

Cada ser humano que nasce é singular, ou seja, se distingue de todos que o antecedem ou virão depois por conseguinte, é potencialmente capaz de trazer algo totalmente novo ao mundo. O fato de estar entre outros singulares o impulsiona a se relacionar e comunicar com os diferentes, estabelecendo assim um âmbito de convivência. Nele cada pessoa pode se revelar em atos e palavras, o que não faria sentido isoladamente, mas ganha sua relevância numa esfera que se estabelece entre as pessoas. Com suas ações, as pessoas constantemente criam e recriam o espaço-entre e, assim, estabelecem um mundo comum-lugar da política e palco das histórias humanas. (ALMEIDA, 20II, p. 23)

Em sua obra A condição humana, Arendt nos mostra que é no momento que agimos em relação ao outro que se revela a nossa singularidade, ou seja, quando nos apresentamos em atos e palavras. Com isso, pode-se dizer ser o outro que descobre a nossa singularidade e não nós mesmos por si próprio. Contudo, o que constitui o mundo é os diversos tipos de opiniões.

Temos em comum não só com aqueles que vivem conosco, mas também com aqueles que aqui estiveram antes e com aqueles que virão depois de nós. (ARENDT, 2010, p. 67)

É de suma importância a instrução e a preparação, pois, esta é a tarefa do educador; visto que, este deve instruir o recém-chegado sobre o mundo e preparar o mesmo para que possa abster-se de sua individualidade e singularidade, sendo assim, o recém-chegado quando jovem estará apto para decidir, tomar suas próprias decisões.

Embora o educador deva estar qualificado para exercer ambas as tarefas, seu maior desafio, no entanto consiste em, ao preparar o espírito jovem para a convivência no mundo, não cair em algum tipo de doutrinação e ideologia ou, no que seria mais desastroso, fazer da escola e da educação um instrumento da política. (MULLER, 2012, p.66)

O papel do educador, então, é de tomar certa responsabilidade pelo mundo e não apenas pelos alunos que ele dirige. Para as crianças, este, o professor, é o que representa-se 
como habitante desse mundo que deles usufruem. Por isso, assumir, proteger e conservar, deve ser a atitude do professor para com este mundo, a fim de apresentar sua importância para os seus novos alunos, ou seja, é ele quem demonstrará autoridade, "porém sua autoridade se assenta na possibilidade que ele assume por este mundo". (ARENDT 20II, p. 239).

Para Arendt representar o mundo é inicialmente tomá-lo como seu, reconhecer e considerar o mesmo como seu próprio meio de vida, independente se este o fará contente ou não, pois, só assim será possível dar um sentido à existência. Receber o recém-chegado é darlhe um "lar", uma casa para que estes se sintam "à vontade". Assim, é que se afirmar a posição de Arendt quando diz que: "na educação, essa responsabilidade pelo mundo assume a forma da autoridade" (ARENDT, 20II, p. 239).

Uma vez que as crianças e jovens se inserem neste mundo, eles passam a familiarizarse e a conhecer o mesmo para, então, começar a caminhar, "dar passos" dentro dele, sendo assim, se responsabilizando por seu espaço e assumindo a sua condição de cidadão no mundo, no seu meio.

Outro ponto importante que Arendt destaca como crítica, é o papel que a autoridade assume na educação, ou seja, do negar-se e da falta que a mesma exerce, seja no espaço educacional ou no espaço político. Assumir o mundo como um "lar" é o papel do adulto, e a partir disso, enxergar este mundo como algo próprio para seu bem-estar, para a sua sobrevivência e não apenas como algo passageiro.

Essa conduta de desresponsabilização pelo mundo ou até de rejeição a ele, impossibilita em princípio, a tarefa educativa. (ALMEIDA, 2011, p.43)

Abandonar a responsabilidade pelo mundo é um dos fatores mais sérios que Arendt aponta, estes devem ser revistos e repensados na educação, pois os adultos não podem se ausentar na vida das crianças, se não lhes for mostrado ou apresentado a elas o mundo que a vivem e a responsabilidade que as mesmas devem assumir sobre quando adultas, não poderão crescer, caminhar em rumo de suas próprias decisões. Por isso, a noção de Crise é uma das ideias fundamentais dos temas abordados pela a autora. Tendo esta noção de "crise" como princípio, Arendt apresenta diferentes pensamentos e fatos que engloba a crise no mundo moderno, dentre elas, a crise no os Estados Unidos e na América Latina.

A crise geral que acometeu o mundo moderno em toda parte e em quase toda esfera da vida se manifesta diversamente em cada país, 
envolvendo áreas e assumindo formas diversas. Na América, um de seus aspectos mais característicos e sugestivos é a crise periódica na educação, que se tornou, no transcurso da última década pelo menos, um problema político de primeira grandeza, aparecendo quase diariamente no noticiário jornalístico. (ARENDT, 2000, p. 221)

$\mathrm{Na}$ obra A condição humana e As origens do totalitarismo, podemos investigar e extrair fenômenos políticos que marcaram séculos anteriores e que resultaram no que Hannah Arendt classifica como a crise na Educação.

Partindo de problemas específicos, ou seja, da insatisfação dos norte-americanos para com seu sistema educacional, Arendt destaca logo de início que seria de fato tentador considerar a crise na educação como um simples acontecimento e sem conexões com as questões principais do século presente.

Assim, os fatores específicos das políticas educacionais locais ou das práticas pedagógicas, ou seja, impasses e incertezas das práticas e dos objetivos educacionais, não se pode desvincular do modo de vida moderna (século XX) que invade as esferas familiar e educacional. Com isso, para que se tenha maior compreensão deste próprio modo de vida e seus impactos no campo da educação é necessário fazer alguns esclarecimentos, sendo o primeiro referente à "noção de crise" e o segundo o próprio conceito de educação no mundo de Arendt.

O conceito de crise originou-se no campo da medicina. A partir do século XIX, ela passa a ser usada na Ciência humanas. Com isso, podemos associar ao termo "crise" noções como "degeneração" e "morte".

A crise para Arendt significa explorar e investigar o que existe no "ser" das questões, a busca uma resposta profunda, a ter um questionamento crítico diante de tais possibilidades, sendo que de tal modo faz com que nos retomemos as mesmas, em buscas de respostas novas e velhas.

Uma crise nos obriga a voltar às questões mesmas e exige respostas novas ou velhas, mas de qualquer modo julgamentos direitos. Uma crise só se torna um desastre quando respondemos a ela com juízos pré-formados, isto é, com preconceitos. Uma atitude dessas não apenas aguça a crise, como nos priva da experiência da realidade e da oportunidade por ela proporcionada à reflexão. (ARENDT, 200o, p. 227). 
Algumas de suas iniciativas nasce da experiência que ele absorve ou retém através da tradição, que de certo modo, algumas vezes serviam como base para tais respostas e os impulsionavam para o mundo. Entretanto, quando acontece essa perda de tradição, esta que vem a nos guiar com as experiências passadas, lançando-nos para um presente em vista de um futuro, Arendt começa a perceber que para melhor compreender o mundo moderno, seria necessário olhar criticamente para o mesmo e recuperar tudo isto que impede o indivíduo retornar em suas experiências passadas, tudo aquilo que ficou na história e, que não foi possível desvendar neste tempo presente.

Para Arendt, só é possível trabalhar a crise na educação quando se faz a ligação entre dois termos, no qual ela apresenta como a ruptura com a tradição, ou seja, com nossa atitude em relação ao passado e, sobretudo, com a perda de autoridade.

Portanto, quando se fala de tradição é preciso retomar a tais experiências, visto que, a mesma impulsionará a busca de desejo contínuo e prezará pelo o respeito à autoridade. Vale ressaltar que o significado da palavra tradição muitas vezes não é passado, mas a memória que temos das coisas e fatos passados, que resguarda a profundidade da existência humana. Sem memória, sem recordação, não há profundidade. Cada qual propõe um "voltar-se" na história para se pensar no futuro, onde, este desejo, o de continuidade é ato de querer abstrair como modelo os nossos antepassados. Com isso, é possível respeitar passado mas tendo em vistas as conquistas que estes obtiveram em busca de respostas que também perambulavam em seus pensamentos.

Sendo assim, pensar no conceito de crise nos remete a ideias de um tempo de incertezas e perigos, mas também nos sugere uma noção de um "tempo decisivo", momento que exige discernimento e intervenção, pois a mesma nos faz voltar ao passado para buscar tais respostas que nos impulsionará ao futuro, sendo assim, nos oferece uma transformação, ou seja, a oportunidade de podermos refletir, investigar e agir. Arendt aponta a "crise" como a perda do senso comum, não no sentido de um saber científico, mas como ausência de significações partilhadas por uma comunidade.

O homem comum se preocupa com problemas atuais, no qual, ele mesmo se depara com o vazio "ele nada sabe". Porém, existe outra razão que o leva a ficar preocupado, visto que o mesmo não está envolvido nessa situação crítica. A própria crise pode oferecer as oportunidades que o homem necessita para "derrubar suas máscaras" e a partir disso, explorar 
tudo aquilo que está na essência do problema, na qual se referem à natalidade, ou seja, o fato dos seres humanos nascerem no mundo. É em sua própria origem que o homem encontra as respostas para as crises presentes.

A educação desde antigamente até os dias de hoje mostra a necessidade de criar um mundo novo, através das crianças que são novas por natureza e nascimento. Pois, o nascimento é o surgimento para a vida, para o mundo, dado que, iniciados nele, trazemos conosco a herança de um legado histórico.

Para Arendt, a educação, está diretamente ligada ao fenômeno de natalidade. Para ela, nascer para a vida é diferente de nascer para o mundo, sendo que nascemos para a vida pelo nascimento e, que através da natalidade é que nascemos para um mundo novo. Nascemos para a vida, para que possamos crescer em nossa subsistência, mas, também, nascemos neste mundo que nos remete ao conjunto de realizações humanas prévias a esse nascimento. A atitude de transformação, de nascer para um mundo novo é o que Arendt classifica como a essência da educação, ou seja, é através da natalidade que se pode haver no mundo uma constante renovação.

A educação é o ponto em que decidimos se amamos o mundo o bastante para assumirmos a responsabilidade por ele e, com tal gesto, salvá-lo da ruína que seria inevitável não fosse a renovação e a vinda dos novos e dos jovens. A educação é, também, onde decidimos se amamos as nossas crianças o bastante para não expulsá-las do nosso mundo e abandoná-las a seus próprios recursos, e tão pouco arrancar de suas mãos a oportunidade de empreender algo nova e imprevista para nós, preparando-as em vez disso com antecedência para a tarefa de renovar um mundo comum. (ARENDT, 2000, p. 247).

A autora faz uma diferenciação entre natalidade e nascimento, entre vida e mundo.

Segundo ela, o nascer tem dupla dimensão. Primeiramente, a natureza biológica ou física, é o fato de que há um novo ser na vida. O nascimento é maneira pela qual a vida se renova e perpetua suas formas.

Assim, pode-se dizer que o mundo no qual as crianças estão a ser introduzidas é um "mundo antigo" construído pelos vivos e pelos mortos, ou seja, a profundidade de nossa existência nunca é dada pelo fato de isolar-se, do indivíduo ficar isolado, mas dada por um mundo muito maior dentre os seres. Com isso, tem-se a possibilidade de fundar uma nova ordem de consciência, um continuum histórico. Portanto, a natalidade indica que cada ser humano além de ser algo novo na vida é um ser novo no mundo. Ela indica, pois, a entrada no 
mundo das realizações simbólicas e materiais de uma cultura e, continuamente na esperança de sua renovação.

Portanto, para Arendt, o que possibilita os indivíduos mais velhos introduzirem os mais novos á entrarem no mundo são suas próprias atitudes humanas, seus modos de vida, ou seja, seus exemplos e suas experiências vivenciadas. É neste fato conservador que o mesmo irá inculcar a renovação, ou seja, proteger o mundo contra tudo aquilo que provém de cada nascimento, para que a partir de sua nova existência, este possa estar protegido das coisas existentes no mundo. Por isso, é necessário preservar a criança ou o indivíduo da novidade adquirida através do nascimento e, assim, introduzi-las em um mundo mais velho do que ela, para que a mesma possa educar-se através da própria natalidade. Sendo assim, pode-se dizer que a novidade trazida pelo recém-chegado e este contato com o mundo velho, leva-nos ao conceito de educação, educar-se. Por isso, é necessário olhar para o passado e que este seja a base para a transformação do futuro, pois os novos se inserem num mundo que já existe, e devem conhecê-lo para nele terem a possibilidade de realizar algo novo.

Assim, que a educação obriga os indivíduos respeitarem o passado em vista de uma continuidade futura, o que foi perdido entre a autoridade e tradição, e a própria essência da educação, é o que Hannah Arendt classifica como crise, no qual, encontra-se presente na modernidade.

Partindo desse pressuposto, pode-se dizer que a crise na educação se prolifera de dois pontos: os fatores pertinentes à crise na autoridade e aos da crise na tradição. Cabe, portanto, compreender agora como que esses dois pontos principais interferem na crise da educação.

Tendo por base as análises políticas educacionais, Arendt no artigo " A crise da educação" norte americana, percebe que a mesma não está alienada às fronteiras nacionais, mas possui uma certa explanação que se relaciona com as principais questões do século. Portanto, compreender a crise é compreender todos os fatores que a engloba, assim, Arendt aponta três pressupostos presentes na crise da educação:

O primeiro é de que existe um mundo da criança e uma sociedade formada entre crianças autônomo e que se deve, na medida do possível, permitir que elas governem. Os adultos estão aí apenas para auxiliar esse governo. A autoridade que diz às crianças individualmente o que fazer e o que não fazer repousa no próprio grupo de crianças [...] e é assim da essência desse primeiro pressuposto básico considerar somente o grupo, e não a criança individual. (ARENDT, 2010, p. 230) 
Sendo assim, com esse primeiro pressuposto, as crianças assumem o papel principal da educação. Quando se exige a responsabilidade das crianças pelo mundo a autoridade se inibe, pois, cabe ao educador a função de auxiliá-las de tal modo que "ele possa apenas dizerlhes que façam aquilo que lhe agrada e depois evitar que o pior aconteça" (ARENDT, 2010, p. 230).

O leque que norteia esse pressuposto faz com que a "autoridade de um grupo, mesmo que esta seja de um grupo de crianças, seja sempre consideravelmente mais forte e mais tirânica do que a mais severa autoridade de um indivíduo isolado"(ARENDT, 2010, p. 230). O que faz com que a libertação da criança do mundo adulto termine, é o abandono aos seus próprios meios, pois a crianças como um ser individual não teria como se situar contra tal opressão. Antes as crianças conseguiam rebelar-se contra um ser superior a elas, pois contava com as demais para o ato solidário, porém agora, tudo aquilo que ela faz encontra-se dentro de um grupo específico de crianças no qual, suas atitudes não podem ser contrárias ao grupo; o que impossibilita cada qual de expressar a sua singularidade como indivíduo.

Esse processo de "emancipação" das crianças tenha sido criado para o benefício das mesmas, porém, não trazer ganhos á elas, visto que "a criança não foi libertada, e sim sujeita a uma autoridade muito mais terrível e verdadeiramente tirânica, que é a tirania da maioria" (ARENDT, 2010, p. 230).

É de suma importância apresentar o segundo pressuposto que, "tem a ver com o ensino. Sob influência da psicologia moderna e dos princípios do pragmatismo, a pedagogia transformou-se em uma ciência do ensino geral a ponto de emancipar-se inteiramente da matéria efetiva a ser ensinada" (ARENDT, 2010, p. 23I). Aqui apresenta-se a preocupação com os métodos de ensinos e as etapas de aprendizagem, cria-se necessariamente a pedagogia como aquilo que irá abranger geralmente o ensino, por isso é chamada da "ciência do ensino", pois nela é que se desenvolverá as habilidades e formas para o novo ensino, a forma de ensinar tudo aquilo que lhes compete.

Os educadores (professores) passam então a ser aqueles que ensinam, porém, não aqueles que conhecem o que ensinam, eis o ponto crucial da afirmação. Uma vez que o professor é aquele que possui autoridade e aquele que representa a tradição para assim governar, ensinar os novos, compete a este transmitir o seu conhecimento sem a imposição da sua autoridade, é preciso criar métodos específicos ou adequados para instaurar o seu ensino. 
Portanto, pensar no terceiro pressuposto é trabalhar hipóteses do pragmatismo, visto que, "só é possível conhecer e compreender aquilo que nós mesmos fizemos, e sua aplicação a educação é tão primária quanto óbvia: consiste em substituir, na medida do possível o aprendizado pelo fazer" (ARENDT, 2010, p. 232).

Contudo, ensinar um conhecimento ou saber não é a coisa mais importante, mas sim, demonstrar, ensinar na prática, agir, praticar uma ação, realizar uma hermenêutica. Tendo isso como afirmação, pode-se concluir que através da habilidade e do saber se constrói o verdadeiro conhecimento no qual é necessário para a vida humana, uma vez que este, encontrase inserido na sociedade que busca por um mundo novo.

\section{REFERÊNCIA BIBLIOGRÁFICA}

ARENDT, Hannah. Origens do totalitarismo. São Paulo: Companhia das letras, 1986.

Entre o passado e o futuro. São Paulo: Perspectiva, 2002.

A crise na Educação. in quatro textos excêntricos. Lisboa: Relógio d'Água, 2000a.

A vida do espírito. o pensar, o querer, o julgar. Rio de Janeiro: Relume Dumará, $2000 b$.

A condição humana. Rio de Janeiro: Forense, 2005a.

Homens em tempos sombrios. São Paulo: Companhia das letras, 20o8b.

CARDOSO JÚNIOR, Nerione N. Hannah Arendt e o declínio da esfera pública. Brasília: Senado Federal, Subsecretaria de Edições Técnicas, 2. ed. 2007.

CORREIA, A. O significado político da natalidade: Arendt e Agostinho. In: Nascimento M. (orgs.). Hannah Arendt: entre o passado e o futuro. Juiz de Fora: UFJF, 2008, p. 15-34. 